\title{
VIAJES Y REGRESOS DE LUIS MIZÓN
}

\section{TRAVELS AND RETURNS OF LUIS MINZON}

\author{
Felipe González Alfonso \\ Pontificia Universidad Católica de Valparaíso, Chile \\ fgonzalez.alfonso@gmail.com \\ Ximena Figueroa Flores \\ Academia de Humanismo Cristiano, Chile \\ xfigueroa@academia.cl
}

Recibido: 07 de noviembre de 2018

Aceptado: 06 de marzo de 2019

Luego de su exilio en 1974, el poeta Luis Mizón (Valparaíso, 1942) ha sido ampliamente reconocido en Francia donde reside hasta la fecha. Ha publicado cerca de cincuenta libros, varios de ellos bilingües, traducidos, entre otros, por Roger Caillois y Claude Couffon, en editoriales tan prestigiosas como Gallimard y Du Seuil. Además, ha sido condecorado como Caballero de las Artes y las Letras (1990) por el Ministerio de la Cultura y la Comunicación de Francia y ha recibido el premio Benjamin Fondane (2014), para escritores francófonos. También es director de la revista Confluence poétiques fundada en 2006, y presidente de la asociación del mismo nombre. Lo anterior contrasta con su poca visibilidad en el panorama poético y crítico nacional, lo que, a sus setenta y cinco años, está comenzando a revertirse. Durante su visita a Chile en el verano de 2017 fue invitado a dos conversatorios: con los académicos de la Universidad de Playa Ancha y con los poetas y arquitectos de la Ciudad Abierta de Ritoque. En el marco de estas actividades conversamos con él en Valparaíso, su ciudad natal.

Para concitar lúdicamente la constelación simbólica de tu obra, te haremos la siguiente pregunta: si tuviéramos que narrar un cuento con los títulos de tus siguientes libros: Poema del sur, Tierra quemada, Provincia perdida, Viajes y regresos, El náufrago de Valparaíso, Marea baja, ¿de qué crees que nos hablaría?

Yo creo que todo se resume al final en el sur, y en la experiencia chilena, la experiencia de la tierra y la experiencia de la historia, las dos cosas. Esta es una tierra y una historia violentas. Bueno, esta violencia ha hecho que tanto la tierra como la historia se oculten, lo que es propio de un escenario de violencia. Entonces esto recorre en otra forma el sendero de mis libros: en la forma de un silencio casi inaccesible, o de una realidad aparentemente accesible, pero como la escuchan los niños en el silencio de la noche, atentos a todos los ruidos que puedan producirse, porque pueden significar alguna cosa. Una mezcla entre el miedo y el asombro. Yo reuní eso en Poema del sur, con la palabra sur. Esto, en realidad, produjo un mal entendido porque el sur en Europa no es nuestro sur; 
cuando los europeos piensan en su sur, piensan en un sur lleno de sol, con esa gente que se ríe todo el tiempo, cantan, etc. No digo que nosotros seamos tristes, pero nuestro sur es mucho más silencioso y no tan asoleado. Y sin embargo, hay elementos comunes. Nuestro sur se parece más a Noruega o al mundo nórdico, pero, a pesar de eso, es como si la palabra sur pudiera englobar dentro de nuestro sur frío el mismo sentimiento de ese sur europeo. Y sobre todo respecto de la historia. Tenemos una historia semejante; los "sures" se unen respecto de la historia aunque tengan climas distintos: la resistencia, un cierto sufrimiento de la historia que se ha padecido. Y además, el sur es una periferia, no es un centro, y nosotros estamos siempre en este sur en un límite, en un extremo, en un extremo límite también respecto del conocimiento. La "tierra quemada" ya sabes que se produce en la guerra, pero también es una forma de enriquecer la tierra con la ceniza. La ceniza tiene un valor simbólico enorme. La ceniza tiene las dos cosas, la fertilidad y la destrucción. Pasemos ahora a la "provincia perdida". Yo era profesor de Historia del Derecho, y la provincia era, en el derecho romano, pro-vincere, una atribución conquistadora y un atributo militar para vencer. Para mí, en mi fuero interno, me decía, nuestra provincia no está completamente perdida, pero finalmente me decidí por decir: nuestra provincia se perdió. Y nombré esta provincia nuestra como un lugar de derrota. Respecto de ese poema Provincia perdida, a mí me había invitado la Fundación Royaumont a un seminario de traducción colectiva con Bernard Nöel, Jacques Ancet y Saúl Yurkievich, y fue traducido entre todos. Con Jacques Ancet jugamos a la escuela, y era él el profesor y nosotros los alumnos. El resultado lo publicaron ellos en los Cuadernos de Royaumont. El título de Viajes y regresos está claro. Desde que me fui de Chile yo empecé a regresar el año setenta y siete, y siempre haciendo el mismo camino al mismo lugar para ver a mi familia, siempre en la misma fecha; no era un viaje turístico, desde luego. Es una experiencia renovada que yo estimaba una forma de conocimiento enriquecedor de lo que no podía conocer de otra forma. Decía yo que no valía la pena viajar, que estaba todo acá en Chile. Mis amigos se habían ido mucho antes y hablaban de la Sorbona, de mayo de sesenta y ocho, y yo seguía insistiendo que realmente no valía la pena viajar. El náufrago de Valparaíso tiene que ver con uno de estos regresos; propuse a France Culture unas emisiones sobre Chile con varios temas: Valparaíso, las minas de Chuquicamata, el sur, los adolescentes en Chile... Doce horas de emisión. Llegué entonces a Valparaíso con la idea de grabar cómo se vivía en dictadura. Al 
mismo tiempo era conocer yo mismo un Valparaíso que nunca había conocido. Ahora llegaba no como profesor de la Escuela de Derecho, si no como un escritor ya bastante conocido en ese momento. Entonces, para entrar de alguna forma indirecta y enriquecedora, para llegar a lo que Valparaíso espontáneamente no me iba a mostrar, encontré un camino nuevo. Veo de repente un letrero en la calle que decía: “Torneo Guantes de Oro". Averigüé más y supe que había un lugar donde los boxeadores se entrenaban y fui con Jacques Taroni a grabar lo que decían. Todo ese mundo me pareció absolutamente increíble, una especie de gran delirio de la decadencia de Valparaíso. Ya sabemos todos los que somos de acá que la decadencia forma parte de nuestra experiencia de Valparaíso. Pero en este local ya era increíble. Los boxeadores se entrenaban con cuerdas para saltar que eran correas de antiguas máquinas Singer. Al mismo tiempo, los espejos rotos, las fotografías, sus historias... Esos boxeadores valientes que reciben castigo y castigo pero que se levantan siempre, hasta el final; ya están ensangrentados, pero no se dan nunca por vencidos y se transforman en una especie de héroes míticos; los otros que quedan un poquito tontitos; los otros que se les olvida lo que han sido; los otros que siguen siendo los entrenadores de fantasmas... Y decidí introducirlos después en mi relato El náufrago de Valparaíso. En Marea baja están los regalos sorprendentes de las mareas bajas de Talcahuano que formaron parte de mi infancia; la oportunidad, provisoria, de internarse en un universo lleno de riquezas.

A propósito de Valparaíso. Teniendo en mente a otros poetas del exilio porteño como Osvaldo "Gitano" Rodríguez, en cuya obra se observa un sentimiento de aguda melancolía o nostalgia, y a Eduardo Embry, que continúa escribiendo en Inglaterra una obra llena de humor y autoironía ¿Cómo abordas en tu poesía la experiencia del exilio?

Conocí mucho más a Osvaldo Rodríguez que a Embry. Lo que escribieron lo conozco muy poco; eso también forma parte de nuestra manera de vivir el exilio. Vivimos muy separados, muy distantes, y no nos preocupamos mucho de leernos y reunirnos, que es lo que ustedes están haciendo y me parece realmente excelente. Yo creo que esas dos posiciones, la posición melancólica y la posición irónica, forman parte de nuestra naturaleza, de nuestra identidad chilena. Somos melancólicos y, de hecho, eso se percibe en nuestra manera de ser. Yo recuerdo qué siente uno al entrar en un café, como el café Riquet, por ejemplo, otro sitio que se fue... qué siente uno ¿Podríamos decir que estamos 
en un café muy alegre, como en un café en Argentina? No, nuestra manera de ser tiene algo de melancolía; algunos han llegado a decir que somos llorones, violentos pero llorones. Me parece exagerado, a pesar de que más de algún chileno es capaz de escenas de violencia tremendas y de llorar como un niño por una película, o incluso leyendo. La melancolía está, además, en nuestro paisaje, en nuestro universo, y la ironía también. Los chistes chilenos son inimitables; la gente se reúne para contarse chistes, y hay en los chistes chilenos una tremenda ironía. No necesitamos, creo yo, cierta ironía que nos ha venido de afuera como si no la tuviéramos aquí. La ironía de Parra es muy chilena, pero también en la poesía centroamericana, en la poesía cubana, hay mucha ironía, se puso en un momento de moda. Pero siempre he pensado que el equilibrio no está en esa ironía que casi forzaba a la poesía; había que ser un poquito brillante siempre, sobre todo en el momento final, como si uno contara un chiste. No; resulta que para la gente que lee poesía en países donde hay una gran cultura poética, esa poesía no es muy interesante, no les llama la atención como a nosotros. En un medio, o en un momento histórico, en que predomina lo melancólico, escuchar un chiste nos hace reír. Pero eso no se puede ni traducir muchas veces, lo que es muy mal síntoma; lo que no se puede traducir significa que tiene aspectos locales que realmente no pueden ser asumidos por otras culturas. La poesía, incluso la poesía irónica o la poesía de circunstancias, debe ser hecha para ser transmitida de un idioma a otro. Es decir, si vamos a algo sumamente local no estamos en la poesía, nos estamos saliendo. Ese es un terreno bastante peligroso, con el prosaísmo se está jugando con fuego, se cae en un momento en que estamos disminuyendo la fuerza poética. Esa es mi posición. Ahora, diciendo eso no quiero decir que yo haya solucionado el asunto. Yo no me encuentro muy irónico, sin embargo, busco la belleza estética en esa experiencia que ha sido relatada por viajeros acercándose a Chile, que lo bello no está forzosamente en lo bonito visible; lo bello, como el resto, está más o menos escondido y aparece de pronto con un asombro, en una intimidad, y ahí aparece de pronto la belleza de lo feo; y ahí aparece, en consecuencia, para el viajero sorprendido con la belleza que está donde no se la esperaba, el enamoramiento. Hay ese enamoramiento de lo feo que se transforma en hermoso. Y no cuando la gente lo espera; y no cuando el que quiere mostrarlo decide, normalmente se equivoca. La voluntad de mostrar lo hermoso muchas veces se equivoca. No está en una intencionalidad, está en un descubrimiento. 
En cuanto a la nostalgia yo creo en ese país portátil, en esas referencias del mundo vivido de la infancia, pero que queda siempre a medias, como un descubrimiento que siempre se está haciendo. Yo creo que Chile me hizo falta, pero tampoco tengo, y hasta me molesta, un culto nostálgico con un patriotismo muchas veces despectivo respecto de otros. El hecho de haber salido de Chile me abrió el horizonte de mi nostalgia, y ya no quedé simplemente nostálgico del sur que conocí cuando niño, o de pasar horas frente a la chimenea en Talcahuano, o en esas cocinas inmensas llenas de cuentos, de hollín, como una pequeña parte del infierno, con una puertecita que se abre... Todo ese mundo absolutamente maravilloso de mi infancia, bueno, eso me lo llevo, a lo mejor ya no existe, pero ya lo tengo. En parte, me encantaría naturalmente encontrarlo, o reencontrarlo. Pero lo que se me dio con el exilio, o saliendo de Chile, fue una apertura de mi mundo nostálgico; ya no soy nostálgico, y me molesta una nostalgia estrecha. Me molesta el dieciocho de septiembre, por ejemplo, en la forma en que pueda vivirse como forzándome la mano para que tenga una cantidad de sentimientos. Así que el patriotismo a la chilena, el mirar mal a nuestros vecinos, no. Yo escribí una novela; lo que vi en Perú me dejó también muy nostálgico, y lo que vi en otras partes, lo que vi antes en la Isla de Pascua, y lo que he visto en otros países sudamericanos, me deja nostálgico en un sentido muy amplio.

¿Crees que el desconocimiento de tu obra en Chile se relaciona con tu condición de exiliado y, más aún, de exiliado porteño o provinciano? ¿Qué piensas del contraste entre el amplio reconocimiento que ha obtenido tu obra en Francia y la escasa atención en Chile?

No cabe la menor duda de que hay un problema. Ahora, ¿cómo explicar esta situación?, ¿en qué forma se puede explicar? Realmente es una especie de fenómeno, y no es un fenómeno que solo se me ha producido a mí en el exilio. Pero hay que tomar en cuenta muchas cosas. La primera es que yo no me fui como poeta, yo me fui como un profesor de Historia del Derecho de la Universidad Católica y de Historia Moderna de la Universidad de Chile. Yo era un asistente de Andrés Orrego Matte en la Universidad de Chile y de Ítalo Merello en la Universidad Católica. Y la Escuela de Derecho no es un lugar en que se valorice la escritura o la poesía, de manera que parto de un medio en que lo que yo hago tengo que hacerlo en secreto porque está desvalorizado alrededor mío. Diferente a los medios culturales de otro orden, en que se valoriza la poesía. Ahora, qué sucedió en el exilio. Los poetas que se fueron ya reconocidos se encontraron con un fenómeno que, 
seguramente -no me puedo poner en la piel de ellos-, debe haberles molestado. Decir: "Bueno, me reconocen; me van a seguir reconociendo, seguramente en el extranjero me van a publicar", y eso no sucede así. A pesar de estar sostenidos por el exilio -el exilio es también un poder- o, después, por el mismo gobierno, no logran reconocimiento afuera. El primer problema es que hay que entender realmente qué es el reconocimiento, cómo se produce, qué es un lector de poesía, y cómo un lector de poesía va a reconocer a un poeta. Eso es sumamente delicado y yo siempre, cuando hablamos de estos temas, digo: un lector de poesía es lo más precioso que existe, es lo más frágil y precioso que existe. Un festival de poesía no vale nada si no hay al lado un lector de poesía, alguien que aprecie, busque la poesía y la lea, y la busque donde sea. Yo conozco la historia, yo era lector de poesía. Y hablo a veces -en prosa o en poesía- de lo que son los lectores de poesía; cómo la buscan, cómo la buscan en los cerros, cómo la encuentran a veces -como yo encontré a Kavafis- en una peluquería, cómo la encuentran en la avenida Argentina, entre los libros, o en las librerías de viejo. Eso son los lectores de poesía; un lector de poesía va a reconocer la poesía, pero esto no puede manejarse. En Europa mi poesía tuvo una suerte extraordinaria de ser traducida, publicada y rápidamente reconocida en medios que están muy acostumbrados a la lectura de poesía y que no admiten la menor presión de orden ni político, ni económico, de ningún tipo, venga de Chile o de Estados Unidos, de cualquier país. Es el lector el que tiene ahí toda la fuerza; sobre todo viniendo de alguien que no puede influir en nada y que, en mi caso, ni siquiera es propiamente un exiliado político, porque no quiere perder la posibilidad de regresar a Chile. Luego está Roger Caillois que no solamente me reconoce, sino que dice: "Lo voy a traducir". "Me va a traducir..."; yo, naturalmente, no lo tomé muy en serio. Si ustedes vieran la plaquette de Las palabras encima de la mesa, ¡es muy fea!, y Caillois la leyó y dijo: "Lo voy a traducir y lo voy a publicar en la Nouvelle Revue Française”. Bueno, a partir de ese reconocimiento se me abrieron otras puertas, hubo otro traductor, pero yo no tenía nada que dar a cambio. Pienso que muchos poetas del exilio esperaban obtener ellos algún tipo de reconocimiento; no lo tuvieron. El reconocimiento francés y, gran parte europeo, lo obtuve yo sin buscarlo en otra forma que presentándole una plaqueta, hecha por mí mismo prácticamente, a Roger Caillois. Y ahora todo lo que escribo lo público todos los años, y hay varias editoriales que me piden que yo publique. Y sé que otros no han podido publicar nada, a pesar de tener 
apoyo, fuerza, universidad, o todo tipo de poderes detrás. Pero este sistema francés no funciona así, no se puede intervenir. Ahora, en Chile, en cambio, sí. Basta, donde hay pocas editoriales, que se cierre una editorial, basta que los dos críticos que hay se callen respecto de alguien, para que esa persona desaparezca del universo. Salvo que en este momento existen otros medios, por ejemplo, internet. ¿Nosotros por qué nos conocemos?, ¿cómo nos conocimos? Nos conocimos por internet, ese fue el medio. Saltamos esta barrera que era cómo conocer a Luis Mizón acá, cuándo realmente los poetas no hablaban de mí, los críticos tampoco. Allá en Francia me publicaban por una razón muy misteriosa, inexplicable. Había, claro, una explicación. Son todos tontos, no conocen nada de la poesía, todos se equivocan: desde Roger Caillois hasta Claude Couffon y Jacques Ancet, y todos los traductores que he tenido, todos se han equivocado, y todas las editoriales se han equivocado también; se equivocó, en la novela, Seix Barral; se equivocó Gallimard; se equivocó Du Seuil. O sea, todos equivocados, esa sería la explicación... Pero no se me ha dado ninguna oportunidad de reconocimiento en Chile. Es un fenómeno que habría que entender como las alteraciones monstruosas producidas por el exilio mismo. El hecho de que yo escriba en francés, por ejemplo, ahora, no justifica que me hayan dejado de lado en los medios hispanohablantes, porque además escribo en castellano y muchos de mis libros son bilingües. Y yo pienso que en este momento se ha producido un fenómeno nuevo, de personas que me han conocido a través de nuevos medios de comunicación, internet u otros. Bueno, todo esto es nuevo, es bastante nuevo, y tenemos el caso de ciertas editoriales que no están tampoco en el medio cultural reconocido, que son un poco marginales, ¿no? Estoy muy contento de que mi reconocimiento en Chile se haga por gente joven y por editores muy marginales. Yo quiero que continúe así. Pienso que mi editor, Manuel Sanfuentes, de Ediciones Al Fragor, va a continuar publicándome. Es lo que él me ha dicho y lo que pensamos hacer.

En una entrevista radial en France Culture, luego de que obtuvieras el premio Benjamin Fondane en 2014, dices que comenzaste a escribir directamente en francés solo a partir del año 2000 ¿Cómo era antes el proceso de traducción desde que escribías un poemario en español hasta que se publicaba en francés?

A mí me tradujo Caillois y me publicó el año setenta y siete un poema que yo había escrito ya en Chile, "Tierra próxima". Cuando Caillois murió, yo había comenzado a 
trabajar en France Culture para hacer crítica literaria para América Latina con Severo Sarduy y Emilio Sánchez Ortiz. Allí conocí, entre otras personas, un traductor, un gran traductor de Neruda, de Vargas Llosa y de otros grandes escritores latinoamericanos, Claude Couffon. Él me dijo, cuando murió Caillois, que él quería traducirme nuevos poemas, y publicar el conjunto, con una introducción de él, en Gallimard. Y le di los otros poemas que aparecen en Poema del sur, "El árbol" y "Poema del sur". Entonces, bueno, ya tenía un traductor. En Francia es el autor con su traductor. Nos invitaban a veces a ciertos coloquios, y a veces en las conversaciones, hablando de otros autores, decía, mirándome: "Él nunca ha traicionado a su traductor". Como el mismo Couffon ha contado, traduce a sus amigos, y nosotros éramos amigos. Conversábamos, o me llamaba o yo lo llamaba, y él me decía: “¿Qué significa esto?”, “qué quiere decir litre?”, “¿qué quiere decir boldo?”, “¿qué quiere decir usted con esto?”. Había una parte de traducción y otra de conversaciones nuestras. Pero él traducía, con una letrita muy chica, escribiendo en el manuscrito entre los versos. El año ochenta y seis, un libro mío que se llama El paso de las nubes, que él tradujo también, bilinguie, se ganó el premio del mejor libro de poesía traducida en Francia, Jean Malrieu, de la revista Sud. La traducción es necesaria, y cada vez más necesaria para circular. Pero llegó el momento en que ya cambié de traductor. Couffon se demoraba mucho con las traducciones y empecé a alejarme por eso y a buscar otros traductores: Nathalie Bréaud tradujo Pasión de la Isla de Pascua; Jacques Ancet tradujo Viajes y regresos y Jardín de ruinas; Laurence Breysse tradujo El Jardín de Luxemburgo. O sea, cada vez traicionaba más a Couffon. Y después me llega el momento de escribir también en francés. El gran problema aquí era: ¿puede uno escribir poesía en otro idioma que no sea la lengua materna? Estamos hablando de traiciones. Aparte de traicionar a su traductor supongamos que sea su padre-, ¿puede uno traicionar al mismo tiempo a su madre? Algunos comentarios de otros que ya la habían traicionado me ayudaron mucho. Beckett, por ejemplo, decía: "Mi lengua materna es el silencio". Yo paso de ahí a la escritura, no entiendo esto de lengua materna. Tenemos el ejemplo de los poetas románticos del siglo XIX ruso, como Pushkin u otros que escribían en francés sin problema. Yo paso de una lengua a otra, vuelvo del francés al castellano y voy del castellano al francés. ¿Por qué? Conversando con Armando Uribe, me decía: "La lengua debe funcionar en los dos casos". Si hay algo que uno no puede traducir, eso me llevaba a ver cuál era el problema que había 
en el original; claro, hay una cosa que debo modificar o sacar. De ahí paso también al sonido; esto fue lo que más me costó, estaba acostumbrado a escuchar mi poesía en español, pero ahora tenía que aprender a escucharla en francés.

Al comenzar a escribir directamente en francés, ¿qué sucede con tu identidad poética? ¿Te consideras un poeta francés?

Yo creo que hay que distinguir entre lengua y cultura. A mí lo que me interesa también es la cultura. Uno pertenece a una cultura que se expresa en la lengua, pero no solamente en la lengua. Por mucho que escriba en francés va a pasar, de todos modos, a mi francés un olorcillo a azufre que viene de Chile, eso es inevitable. De hecho, uno lo ve en otros autores que escriben en francés, pero que son totalmente latinoamericanos. Escribiendo en francés y creyendo a veces que realmente estoy escribiendo en francés, los franceses que me leen dicen: "Pero qué fantástica esta escritura de latinoamericano, este escritor latinoamericano". Porque lo que estoy diciendo en francés, no lo puede decir un francés. La cultura latinoamericana es tan fuerte que llega a tergiversar, a manejar la lengua francesa. Dicen que ha persistido en nosotros el surrealismo, pero esa es una mala interpretación. Yo me paseo en Chile y voy a comprar al mercado y las escenas que estoy viendo las describo: describo la dama que pasa sobre un gato que agoniza, describo las montañas de cabezas cortadas de reses, con sus cuernos, y me dicen: "Pero no, estás imitando a Dalí'”. En absoluto, estoy describiendo la realidad tal cual. No es surrealismo, es la fantasía vital, vivida, en la realidad. Armando Uribe me decía que había leído una crónica chilena sobre la vida de los enanos en Chile; que les pegaban, todos querían ser boxeadores... La gente puede reírse perfectamente de un enano. Cuando yo llego a Chile digo: "Vamos a ver". Todavía no he visto ningún monstruo, pero estoy esperando, luego van a aparecer. Hasta que lea en la noticia del diario: "Extraño ser se vio deambulando...", ¿no?, y aparezcan cosas así. Me ha ocurrido en Francia conversar con una niña bastante joven y me dijo que había estado en Bretaña en una parte, y que en la casa nadie podía subir por una determinada escalera, pero lograron subir y había una luz que andaba por la ventana, y vieron una cuna... En un momento se me ocurrió preguntarle: “¿Oye, eres chilena?" Y me dijo: "No, no, no, no soy chilena, pero mis padres son chilenos". "Ah, yaaa...", le dije. 
En tu último libro, L'île dont le yeux regardent le ciel (2016), se intenta establecer un diálogo con una cultura ancestral, la de Isla de Pascua, de la que poseemos escasos datos para su comprensión ¿Cómo dialoga tu libro con Alturas de Macchu Picchu (1946) de Neruda, donde también el poeta se erige como portavoz de una cultura olvidada?

Considero a la Isla de Pascua en su historia como un resumen o un símbolo de la historia misma del resto de América Latina, en que nos encontramos con una sociedad desaparecida, con un pasado inaccesible, con una lengua indescifrable. Dicen que han avanzado muchísimo, aunque todavía no en forma completa, en las lenguas de México o Perú. Se dice que no existía lengua escrita, pero existían sistemas de memorización... Pero hay un acceso a la cultura, que está allí, muda. El poeta tiene una posibilidad frente a la cultura muda, de hecho: interpretar lo que quedó. En el caso de la Isla de Pascua algo quedó; en el caso de América Latina también. Entonces el poeta se transforma en una especie de arqueólogo o de historiador, pero también ve el presente. En toda poesía hay cierta impregnación histórica, una presencia fantasmática de ese pasado desaparecido que se manifiesta "en voz baja". Hay una serie de puntos que coinciden con el poema de Neruda: ese acercamiento, ese silencio, esa presencia de lo desaparecido sentida por el poeta. Pero en Neruda hay una asimilación del pasado en el presente en tanto existe en ambos una misma injusticia que él como poeta social va a acusar y reivindicar. Esa parte que es la parte final de Alturas de Macchu Picchu es diferente a la parte del comienzo; yo estoy en el comienzo de Macchu Picchu, no en el final. Ese acercamiento a Macchu Picchu es el que yo recojo en mi acercamiento al mundo desaparecido de la Isla de Pascua. Pero yo no acuso a nadie. Salvo en un solo poema en que los que levantan estatuas dicen: "Hemos trabajado tanto / y nadie ha venido / a pagarnos / nadie nos ha traído de beber o de comer / hay solamente una explicación / esta tierra nos pertenece / y no lo sabíamos”. El mundo enterrado de la Isla de Pascua es el que yo interrogo a través de una producción primera, de una materia poética, de etimologías que he reunido de ciertos sitios tratando de ser fiel en latitud y longitud a cada sitio; cada sitio con su poema, y ese poema nace de un conjunto de etimologías que actúan una sobre otra para producir la greda del poema. La Isla de Pascua dejó relatos, entre las cartas de los misioneros, entre las etimologías, pequeños relatos... Con eso yo busco la materia. Por ejemplo, las crónicas del descubrimiento de Isla de 
Pascua del diario de Roggeveen dicen que los marineros buscaban oro, naturalmente, siempre andan buscando oro, buscaban joyas. Veían a las mujeres adornarse, hermosísimas, que brillaban... Después se dieron cuenta que, horror, no había oro: eran conchitas. Entonces, me preguntaba en mi texto de meditaciones sobre estos momentos de Isla de Pascua, La isla de los gigantes amnésicos, pronto a publicarse, con qué conchitas se adornaban. Tengo una teoría, estoy casi seguro de saber con qué conchitas se adornaron las mujeres ese día, porque hay ciertas conchitas que son sumamente valiosas porque existen solo a gran profundidad, y no están fijas en las rocas, sino en las algas... Cualquier mujer hubiera buscado no las conchitas que tú te agachas y encuentras un puñado, sino las más raras, las más especiales. Es decir, la recuperación de lo cotidiano. No quiero ser cínico, pero a veces el hecho de que haya un gran silencio sobre una cultura, permite toda clase de sueños y de ensueños, y de acercamientos poéticos. Los arqueólogos no lo hacen: lo que quedan son testimonios de segunda mano. Yo con un amigo, Zéno Bianu, un poeta francés de origen rumano, hicimos una antología de la poesía precolombina y la publicamos en Du Seuil. Nosotros dijimos: "No sabemos la lengua, pero ellos tampoco". Estamos frente a testimonios de segunda mano: todos son de segunda mano. Y resulta que estos arqueólogos, especialistas, se contradicen: uno dice una cosa y el otro dice otra cosa. ¿Por qué va a ser nuestra visión menos legítima que la de estos sabios que se contradicen totalmente sobre el texto?

Por último. Varios de tus libros se acompañan por trabajos visuales de distintos artistas, y tú mismo practicas el dibujo y la pintura. Nos gustaría saber, ¿qué relación existe entre tu obra poética y el arte visual?

Siempre he pintado, no es una cosa reciente. Cuando estaba ya en el Liceo de Viña, donde estudié hasta quinto año de humanidades, y después en sexto año de humanidades en los Padres franceses de Viña, siempre hacía dibujo, y además era buen alumno. Me sentaba adelante y no molestaba a nadie, pero no hacía los dibujos que decían que hiciera, hacía otros dibujos. Y en realidad algunos profesores no aceptaron esto, a veces sencillamente me echaban de la clase. Al final los padres franceses me habían echado sistemáticamente de la clase durante todo el año, pero yo seguía dibujando en mi casa y presenté estos dibujos al examen, sin decirle nada al profesor, lo que les cayó muy bien a los examinadores, que además felicitaron al profesor por haberme dado la libertad de dibujar. Para mí esto tiene un 
cierto ritmo, muchas veces he dibujado pero no he escrito al mismo tiempo, porque siempre me ha presentado ciertos problemas. Cuando yo veo manchas, y nada más que manchas, puedo decir: estas son las buenas manchas, estas son las malas manchas. ¿En qué me estoy basando? Puedo responder, pero la verdad es que hay un lenguaje que es ininteligible, aunque preciso. Porque cuando me pregunto por las manchas, yo sé cuáles son las buenas, y si le pregunto a muchas otras personas casi todas indican perfectamente la buena mancha. Yo descarto como materia estética, tanto los dibujos de los niños como los dibujos de los locos, porque son demasiado auténticos. El dolor no está en el dibujo del niño, o solo está en un sentido psicológico, pero es que esto va más allá: los dibujos que parecen como de niño, que hacen a veces grandes pintores, esos son los dibujos artísticos; los dibujos donde está no el niño que pinta, sino la niñez. Es muy difícil de explicar que sustitutos, qué mezclas puede haber. Es mucho más claro con las imágenes de películas, porque hay ahí también imágenes, fotográficas, que después se transforman en imágenes que uno cree haber vivido, que dan grandes espacios, grandes referencias que uno integra. Estamos en un mundo totalmente irracional. La poesía está muy cerca de las manchas o de las imágenes y sus sensaciones. Cómo transmito lo que para mí es una imagen mental, totalmente representada en mi cabeza; si pienso en este momento en una imagen fuerte, a lo mejor mi referencia es la misma que viví en la niñez: la diferencias entre el afuera y el adentro, ese asombro de entrar en una pieza mientras el mundo permanece afuera. Mi padre que tenía una gran sensibilidad también poética, me dijo un día: "Ven a la ventana, te voy a mostrar una cosa. Fíjate que los árboles tienen un ritmo, se mueven según la música. Si yo pongo una música te vas a fijar”. Y puso Beethoven, y yo me quedé mirando los árboles y escuchando la música de Beethoven, y yo decía: "Tiene toda la razón. Se están moviendo exactamente de acuerdo a la música". Hay a lo mejor un tipo de continuidades que nosotros no estamos en condiciones de reconocer, pero que existen entre el mundo de lo visual, de lo auditivo y del lenguaje. La imagen tiene otra cualidad que me parece esencial en la poesía, y es la permanencia y el hecho de que se desintegre, por decirlo así, sin deshacerse, porque no es lógica, persiste a pesar de desintegrase: tiene una permanencia, una disolución unida a una permanencia. Para explicarme esto pensé yo que había como imágenes madre, ciertas imágenes que acompañan los textos y que en cierto modo son referencias que puedo después desarrollar. Yo tenía un amigo que trabaja en la traducción de los codex mexicanos 
y decía: "Son poemas, todos son poemas". Los reyes mexicanos, los príncipes, eran todos poetas, porque la escuela enseñaba eso como en China antigua; se enseñaba la poesía como una ciencia, y además la pintura. La pintura para poder pintar los poemas, escritos a pinceladas. Escribir, pintar y hacer un poema, era todo lo mismo.

26 de enero de 2017, cerró Los Placeres

Bibliografía

Mizón, Luis.Mata ki te rangi. L'île dont les yeux regardent le ciel. Montpellier : Méridianes, 2016.

Mizón, Luis. Marée basse suivi de Six arbres. Baume-les-Dames : Æncrages \& Co, 2012.

Mizón, Luis. Le naufragé de Valparaiso. Baume-les-Dames : Æncrages \& Co, 2008.

Mizón, Luis. Voyages et retours. Bilingüe. Trad. Claude Couffon. Le Poiré-sur-Vie : Obsidiane, 1989.

Mizón, Luis. Passion de l'Ile de Pâques. Bilingüe. Trad. Nathalie Bréaud. Paris : La Manufacture, 1988.

Mizón, Luis.Province perdue. Trad. colectiva. Paris : Les Cahiers de Royaumont, 1988.

Mizón, Luis. Passage des nuages. Le Muy, Francia : Unes, 1986.

Mizón, Luis. Terre brûlée. Bilingüe. Trad. Claude Couffon. Paris : Le Calligraphe, 1984.

Mizón, Luis. Poème du Sud. Bilingüe. Trad. Roger Caillois y Claude Couffon. Paris: Gallimard, 1982.

Mizón, Luis. Las palabras encima de la mesa. Valparaíso, Chile: Escuela de Derecho de la Universidad de Chile, 1972. 